\title{
ARTICLE
}

Received 14 Oct 2013 | Accepted 11 Mar 2014 | Published 8 Apr $2014 \quad$ DOl: 10.1038/ncomms4621

\section{Selective and mild hydrogen production using water and formaldehyde}

\author{
Leo E. Heim ${ }^{1}$ Nils E. Schlörer ${ }^{1}$, Jong-Hoo Choi ${ }^{1} \&$ Martin H.G. Prechtl ${ }^{1}$
}

With the increased efforts in finding new energy storage systems for mobile and stationary applications, an intensively studied fuel molecule is dihydrogen owing to its energy content, and the possibility to store it in the form of hydridic and protic hydrogen, for example, in liquid organic hydrogen carriers. Here we show that water in the presence of paraformaldehyde or formaldehyde is suitable for molecular hydrogen storage, as these molecules form stable methanediol, which can be easily and selectively dehydrogenated forming hydrogen and carbon dioxide. In this system, both molecules are hydrogen sources, yielding a theoretical weight efficiency of $8.4 \%$ assuming one equivalent of water and one equivalent of formaldehyde. Thus it is potentially higher than formic acid ( $4.4 \mathrm{wt} \%$ ), as even when technical aqueous formaldehyde (37 wt\%) is used, the diluted methanediol solution has an efficiency of $5.0 \mathrm{wt} \%$. The hydrogen can be efficiently generated in the presence of air using a ruthenium catalyst at low temperature.

\footnotetext{
${ }^{1}$ Department of Chemistry, University of Cologne, Greinstrasse 6, 50939 Koeln, Germany. Correspondence and requests for materials should be addressed to M.H.G.P. (email: martin.prechtl@uni-koeln.de)
} 
A major challenge in chemical science nowadays is to discover new approaches resolving the worldwide demands regarding more efficient energy storage systems. One promising solution involves hydrogen as an alternative energy carrier and feedstock for environmental and economic reasons. In particular, hydrogen storage is of great interest in combination with direct hydrogen fuel cells as efficient energy conversion systems ${ }^{1-3}$. The competitiveness of hydrogen and its superior energetic properties $\left(123 \mathrm{MJ} \mathrm{kg}^{-1}\right)$ in comparison with fossil fuels (diesel: $46 \mathrm{MJ} \mathrm{kg}^{-1}$ ) is still restricted owing to delivery problems. In particular, physical options such as high pressure and cryogenic storage suffer from the containers' heavy weight and safety problems ${ }^{4}$. Therefore, one alternative is chemical hydrogen storage in molecular materials in which the dihydrogen is stored in the form of hydridic and protic hydrogen. Examples are metal hydrides ${ }^{4-6}$, ammonia borane derivatives ${ }^{2,3,7}$, formic acid $^{2,8-17}$ and methanol ${ }^{18-21}$. Ammonia borane derivatives have a good weight efficiency $\left(\leq 19.4 \mathrm{wt} \% \mathrm{H}_{2}\right)^{2,3,7}$, but the solid spentfuels are hardly recyclable. Formic acid-based systems are robust ${ }^{8,15,16}$, but the $\mathrm{H}_{2}$ weight efficiency is quite low (4.4 wt\% $\mathrm{H}_{2}$ ), and so far low-temperature methanol-based systems $\left(12.5 \mathrm{wt} \% \mathrm{H}_{2}\right)^{18}$ are limited to inert conditions, as the nature of the catalysts is sensitive to air and might decompose under oxidative conditions. Moreover, the formic acid and methanol dehydrogenation require additional base, which is a drawback for the weight efficiency. Water $\left(11 \mathrm{wt} \% \mathrm{H}_{2}\right)$ as a sole source of hydrogen is desirable as it is cheap and readily available, but so far water-splitting schemes need large amounts of energy for the electrochemical, photolytic or thermal process ${ }^{22,23}$. Also, homogeneous water-splitting is rare and so not yet very suitable for application in terms of efficiency and significant hydrogen yields ${ }^{24}$. Formic acid and methanol have the advantages that only gaseous products $\left(\mathrm{H}_{2} / \mathrm{CO}_{2}\right)$ are formed, and in presence of molecular ruthenium catalysts no relevant $\mathrm{CO}$ and methane formation occurs $8,16,18$. In addition, these factors are crucial for mobile applications with hydrogen fuel cells where the formation of solid and liquid by-products as well as $\mathrm{CO}$ as a catalyst poison are detrimental for fuel cell catalysts.

In our research on molecular hydrogen storage systems, we focus on low-temperature $\left(40-140{ }^{\circ} \mathrm{C} ; 313-413 \mathrm{~K}\right)$ hydrogen generation with non-inflammable compound mixtures with weight efficiencies of $4-13 \mathrm{wt} \% \mathrm{H}_{2}$ (refs 7,8,25,26). Interestingly, early reports about hydrogen production using methanol ${ }^{20}$ or formic acid ${ }^{17}$ go back to the early 1960s, but homogeneouscatalysed formaldehyde (FA)-assisted water-splitting has not been reported, to the best of our knowledge, in the last 5 decades. Moreover, the 'renaissance' for formic acid-based catalytic hydrogen production started only in 2008 (refs 15,16). Most recently, in 2013, homogeneous methanol reforming under basic conditions has been reported for the first time ${ }^{18}$. However, methanol steam reforming is well known with solid phase catalysts at high temperatures ${ }^{21,27-33}$, and intensively investigated with copper and zinc oxide catalysts $27-29,31,32$.

Here we report a one-pot process with two dehydrogenation steps in aqueous media containing FA, where water acts as a hydrogen source as well. In the present work, we show that paraformaldehyde (pFA) and FA together with water are suitable materials for catalytic hydrogen production with defined selectivity and tolerance to oxygen-containing atmosphere. The process solely gives good yields of hydrogen and carbon dioxide in pure form. Owing to the long-term stability/recyclability, nonflammability and a theoretical $\mathrm{H}_{2}$ weight efficiency of $8.4 \mathrm{wt} \%$, considering 1 eq. $\mathrm{H}_{2} \mathrm{O}$ and $\mathrm{H}_{2} \mathrm{CO}$ forming stable methanediol (vide infra), this molecule is potentially interesting for mobile applications. The hydrogen content of methanediol is still higher than formic acid (4.4 wt\%), even when technical aqueous FA
(37 wt\%) is used. Such diluted methanediol solution has a minimum efficiency of $5.0 \mathrm{wt} \%$. Taking into account that the hydrogen from FA-assisted water-splitting can be used for fuel cells, it is advantageous that the oxygen, which is formally formed during a direct water-splitting reaction, is trapped simultaneously in the form of carbon dioxide. Consequently, the oxygen is not available for oxidation, avoiding deactivation/oxidation of the fuel cell catalyst. Moreover, the formation of explosive mixtures of hydrogen and oxygen gas (oxyhydrogen) is avoided and hydrogen is generated in a non-flammable liquid, which is safer than the application of methanol systems. Besides, mixtures of hydrogen and carbon dioxide are easier to handle and to separate than an oxyhydrogen gas mixture $\left(\mathrm{H}_{2} / \mathrm{O}_{2}\right)$. All these aspects make the FAassisted water-splitting interesting for hydrogen production and complementary to the proposed methanol economy ${ }^{21,33}$. In addition, this catalytic conversion of aqueous FA might be an interesting approach for decontamination treatment of wastewater containing FA impurities, which can be easily converted into carbon dioxide and hydrogen. Beyond that, another potential application of this system is that the produced hydrogen can be used directly in transfer-hydrogenation reactions in organic synthesis. In the following, we describe the formation of hydrogen from aqueous $\mathrm{FA}$ and $\mathrm{pFA}$, the composition of the gaseous and liquid phase in this process with isotopically labelled substrates, characterization of the catalyst species and the catalyst performance and its isolation.

\section{Results}

Methanediol formation and dehydrogenation. The lowtemperature reforming of $\mathrm{pFA}$ and $\mathrm{FA}$ in aqueous solution is catalysed by the commercially available $\left[(\mathrm{Ru}(\mathrm{p} \text {-cymene }))_{2}\right.$ $(\mu-\mathrm{Cl})_{2} \mathrm{Cl}_{2}$ ] 1 as the catalyst precursor, which was previously investigated in-depth for the decomposition of formic acid ${ }^{8}$. Contrary to the formic acid decomposition, no catalyst preactivation with base is needed for the pFA/FA decomposition. In water, it is known that FA is in principal solely present in the hydrated form as methanediol ${ }^{34,35}$. The equilibrium constant for methanediol/FA is $K_{c}=2 \times 10^{3}$ in contrast to $K_{c}=2 \times 10^{-3}$ for 2,2-dihydroxypropane/ acetone $^{34,35}$. Therefore, hydrated FA makes water accessible for dehydrogenation in aqueous solution, where methanediol acts as the hydrogen source. Thus, in the homogeneous processing of methanol or FA in an aqueous dehydrogenation reaction to $\mathrm{CO}_{2}$ and $\mathrm{H}_{2}$, it is more likely that the coordinated methanediol plays a role rather than the side-on coordination of the FA as proposed elsewhere $^{18}$. Considering that FA is produced by methanol oxidation (Formox process) with water as a by-product, the protic hydrogen atoms in methanediol are originally derived from methanol due to hydrolysis of FA (Supplementary Fig. 1).

Methanediol contains two pairs of protic and hydridic hydrogen atoms per unit resulting in two equivalents of hydrogen gas (Fig. 1). Equally to formic acid all protic and hydridic hydrogens in methanediol are accessible for dehydrogenation, resulting in a weight efficiency of $8.4 \mathrm{wt} \% \mathrm{H}_{2}$ per molecule. Thus, FA acts as a hydride donor and water as a proton donor, which represents a FA-based molecular approach for indirect watersplitting. The dehydrogenation of methanediol probably occurs in a two-step reaction, where the methanediol is converted into formic acid under hydrogen evolution $\left(1^{\text {st }}\right.$ eq. $\left.\mathrm{H}_{2}\right)$, and then the formic acid is further converted into carbon dioxide and hydrogen $\left(2^{\text {nd }}\right.$ eq. $\mathrm{H}_{2}$ ).

Previous reports about formic acid and methanol showed that the presence of at least catalytic amounts of base is crucial for the successful dehydrogenation of the hydrogen carrier $8,15,16,18$. In contrast, we found that the dehydrogenation of methanediol 
derived from FA or pFA is possible also in absence of base additives (Supplementary Fig. 2: $37 \mathrm{wt} \%$. aqueous FA solution). However, the addition of base shows some positive effect and accelerates the dehydrogenation reactions carried out at ambient pressure. The efficiency of the catalytic dehydrogenation depends on the applied temperature with the best catalyst performance at $95^{\circ} \mathrm{C}(368 \mathrm{~K})$. High hydrogen yields $(84 \%)$ were already achieved within short reaction time $(<60 \mathrm{~min})$ and recharge of the catalyst solution was possible by adding $\mathrm{FA}$ or $\mathrm{pFA}$ to the reaction mixture.

Composition of the gaseous and liquid phases. Taking into account the proposed reaction sequence in Fig. 1, the gaseous phase was monitored by means of sensitive mass spectrometry (MS) techniques (see Methods). Herewith a semiquantitative characterization of the gaseous phase composition, besides the quantification with mass-flow meters, was obtained. Indeed, the time-resolved MS analysis confirms that in the initial period the composition contains much larger amounts of hydrogen rather than carbon dioxide (Supplementary Figs 3,4a). It should be pointed out that neither FA nor CO is present in significant amounts in the gaseous phase as confirmed by labelling experiments with ${ }^{13} \mathrm{C}$-pFA and $\mathrm{H}_{2}^{18} \mathrm{O}$, which underlines the robustness (no FA extrusion) and the selective dehydrogenation as no relevant CO formation is observed (Supplementary Figs 3,4a,b; Fig. 2). This stays in agreement with previous studies using formic acid, where no $\mathrm{CO}$ formation has been observed by MS and gas chromatography analysis ${ }^{8}$. Note, a residual MS signal in Fig. 2 at $29 \mathrm{~m} / z$ can be assigned to natural ${ }^{14 / 15} \mathrm{~N}_{2}\left({ }^{14} \mathrm{~N}\right.$ : $99.634 \%$ and ${ }^{15} \mathrm{~N}$ :
$0.366 \%$ ) and a residual signal at $30 \mathrm{~m} / z$ can be assigned to $\mathrm{NO}$ formed under MS conditions (also present as a background signal of analysed air). The absence of FA and $\mathrm{CO}$ is important to guarantee high efficiency for fuel cell applications, as it is known that formic acid can decompose to $\mathrm{CO}$ and water at elevated temperature ${ }^{36}$.

During the ongoing reaction, the composition of the gaseous phase changes. In the late step, the gas stream contains relatively more carbon dioxide in comparison with hydrogen than in the initial step (Supplementary Fig. 3). Therefore, it is more likely that first methanediol is converted into formic acid and one equivalent of hydrogen, and then formic acid is converted into hydrogen and carbon dioxide. Indeed, the nuclear magnetic resonance (NMR) analysis of an aliquot showed that reasonable amounts of formic acid (15.6\%) are formed during the course of the reaction. This indicates that the following formic acid dehydrogenation plays a major role after high conversion of methanediol into formic acid and hydrogen.

To obtain further information about the dehydrogenation pathway and the composition of the gaseous phase and species in the liquid phase, the substrate scope was extended to isotopelabelled compounds such as deuterated FA in deuterium oxide (Supplementary Table 1; entry 2) and pFA labelled with ${ }^{2} \mathrm{H}$ and ${ }^{13} \mathrm{C}$. The pFA easily forms FA under slightly acidic conditions, in fact the $\mathrm{pH}$ of distilled water used and stored under air is acidic enough owing to the dissolved $\mathrm{CO}_{2}$, but a small amount of acid additive is beneficial. The solvation of $\left[(\mathrm{Ru}(\mathrm{p} \text {-cymene }))_{2}\right.$ $\left(\mu-\mathrm{Cl}_{2} \mathrm{Cl}_{2}\right] \mathbf{1}$ in water results at $\mathrm{pH}>5.0$ in the formation of $\left[(\mathrm{Ru}(\mathrm{p}-\text { cymene }))_{2}\left(\mu^{2}-\mathrm{OH}\right)_{3}\right]^{+} \quad \mathbf{2}$ and free chloride ${ }^{37}$, thus providing a sufficiently acidic condition/environment. To yield

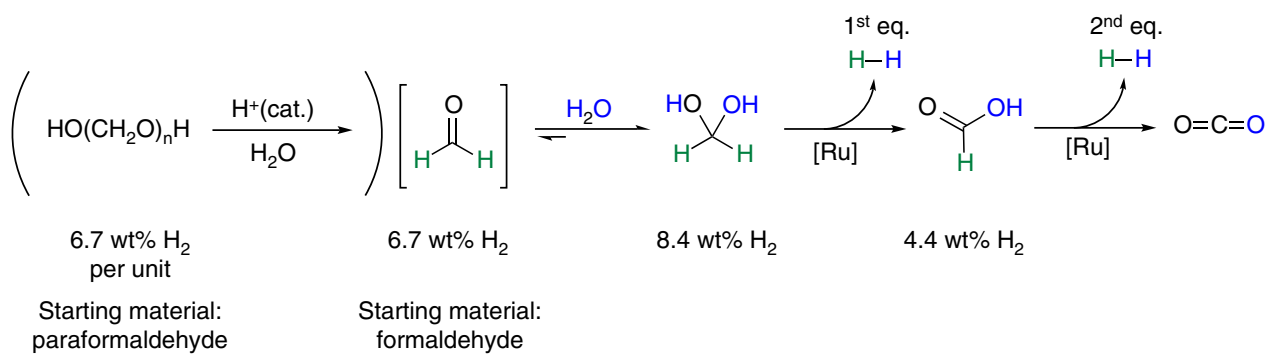

Figure 1 | Reaction pathway. Proposed reaction sequences using paraformaldehyde or formaldehyde as a hydride source and water as a proton source for the subsequent hydrogen generation.

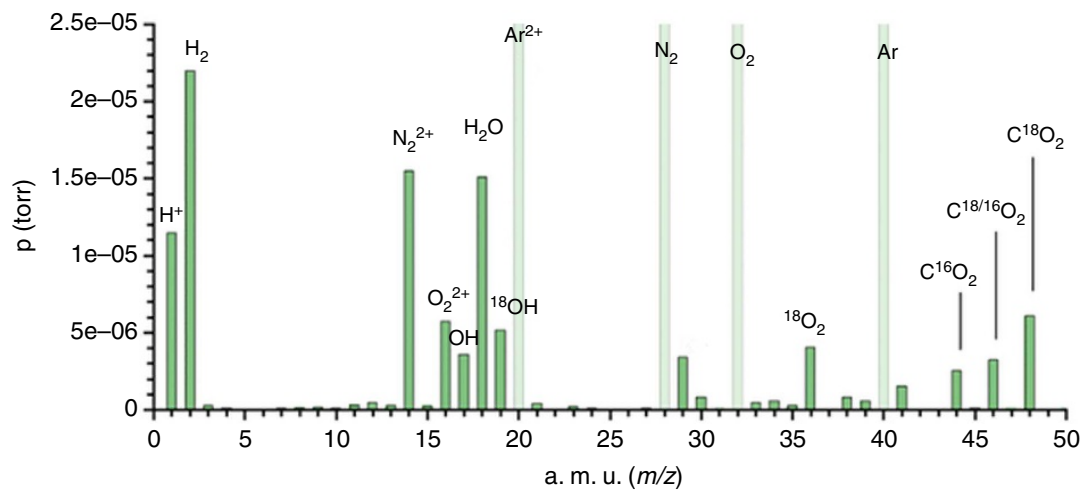

Figure 2 | Mass spectrogram of isotope-labelling experiment with $\mathbf{H}_{\mathbf{2}}{ }^{\mathbf{1 8}} \mathbf{O}$. Gaseous phase analysis of the pFA decomposition in presence of ${ }^{18} \mathrm{H}_{2} \mathrm{O}$ under air with argon as the carrier gas; the peak at $18 \mathrm{~m} / \mathrm{z}$ may include intensity of trace amounts of ${ }^{18} \mathrm{O}_{2}{ }^{2+}$ and the peak at $20 \mathrm{~m} / z$ may include traces of $\mathrm{H}_{2}{ }^{18} \mathrm{O}^{+}$. The intensive peaks related to argon, nitrogen and oxygen are depicted as dashed bars (for full spectrogram see Supplementary Fig. 5). Note, a residual MS signal in Fig. 2 at $29 \mathrm{~m} / \mathrm{z}$ can be assigned to natural ${ }^{14 / 15} \mathrm{~N}_{2}+\left({ }^{14} \mathrm{~N}: 99.634 \%\right),\left({ }^{15} \mathrm{~N}: 0.366 \%\right)$ and a residual signal at $30 \mathrm{~m} / \mathrm{z}$ can be assigned to $\mathrm{NO}^{+}$formed under MS conditions (also present as background signal of analysed air). 
further insights on the reaction mechanism, we performed a series of experiments with non-deuterated (Supplementary Table 1; entries 3-5), deuterated (Supplementary Table 1; entries 7-9) and ${ }^{13} \mathrm{C}$-labelled (Supplementary Table 1, entries 10-12) pFA with $\mathrm{H}_{2} \mathrm{O}$ (Supplementary Table 1, entries 3, 9 and 10), $\mathrm{D}_{2} \mathrm{O}$ (Supplementary Table 1, entries 4, 7 and 12), HDO (Supplementary Table 1, entries 5, 8 and 11) and $\mathrm{H}_{2}^{18} \mathrm{O}$ (Supplementary Table 1, entry 6; Fig. 2). The monitoring of the gaseous phase by MS and the analysis of the liquid phase by NMR and electrospray ionization (ESI)-MS give further information about the reaction pathways and the ruthenium species.

The gaseous phase analysis by MS of the labelled experiments provides evidence that both water and (para)FA are the sources of the hydrogen. With $\left(\mathrm{HO}\left(\mathrm{CH}_{2}\right)_{n} \mathrm{H}\right)$ in $\mathrm{H}_{2} \mathrm{O}$ hydrogen and carbon dioxide are detected in the gaseous phase (Supplementary Table 1, entry 3), likewise for $\left(\mathrm{DO}\left(\mathrm{CD}_{2}\right)_{n} \mathrm{D}\right)$ in $\mathrm{D}_{2} \mathrm{O}$ we detected $\mathrm{D}_{2}$ and $\mathrm{CO}_{2}$ (Supplementary Table 1, entry 7). One could expect that the dehydrogenation of non-deuterated pFA $\left(\mathrm{HO}\left(\mathrm{CH}_{2}\right)_{n} \mathrm{H}\right)$ in $\mathrm{D}_{2} \mathrm{O}$ results in dominating formation of $\mathrm{HD}$ gas, with the deuteron originating from $\mathrm{D}_{2} \mathrm{O}$ and the hydride from the pFA (Supplementary Table 1, entry 4). Interestingly, we observed the following order of formation: with highest abundance, $\mathrm{D}_{2}$ was detected, followed by $\mathrm{HD}$ and then $\mathrm{H}_{2}$. Similar observations were made with dinuclear ruthenium carbonyl complexes for the dehydrogenation of partially deuterated formic acid $\mathrm{HCO}_{2} \mathrm{D}$ or $\mathrm{DCO}_{2} \mathrm{H}$. Here the authors reported the initial predominant formation of $\mathrm{H}_{2}$, followed by $\mathrm{HD}$ and $\mathrm{D}_{2}$ formation ${ }^{38}$. This indicates that $\mathrm{H} / \mathrm{D}$ scrambling is catalysed by a ruthenium species between the $\mathrm{D}_{2} \mathrm{O}$ and the $\mathrm{C}-\mathrm{H}$ bonds of the in situ-generated methanediol previous to the dehydrogenation to formic acid, and it proves that water acts as a source of hydrogen, as methanediol is only formed from FA in the presence of water. Note, in our experiments $\mathrm{H} / \mathrm{D}$-exchange was observed by ${ }^{1} \mathrm{H}$ and ${ }^{2} \mathrm{H}$ NMR analysis of the $\mathrm{Ru}-\mathrm{H}$ and water signal $\left(\mathrm{H}_{2} \mathrm{O} / \mathrm{HDO} / \mathrm{D}_{2} \mathrm{O}\right)$. Vice versa, the experiment with deuterated pFA $\left(\mathrm{DO}\left(\mathrm{CD}_{2}\right)_{n} \mathrm{D}\right)$ in $\mathrm{H}_{2} \mathrm{O}$ resulted mainly in the formation of $\mathrm{H}_{2}$, followed by $\mathrm{H} / \mathrm{D}$ and only traces of $\mathrm{D}_{2}$ (Supplementary Table 1, entry 9). The lack of $\mathrm{D}_{2}$ in the gaseous phase can be explained, as significant amounts of $\mathrm{D}_{2} \mathrm{O}$ have been formed and detected, which proves the H/D scrambling between $\mathrm{H}_{2} \mathrm{O}$ and the $\mathrm{C}-\mathrm{D}$ bonds of the in situformed $\mathrm{D}_{2}$-methanediol (Supplementary Table 1, entry 9). The treatment of $\left(\mathrm{DO}\left(\mathrm{CD}_{2}\right)_{n} \mathrm{D}\right)$ with $\mathrm{HDO}$ shifts the formation to $\mathrm{HD}$, while $\left(\mathrm{HO}\left(\mathrm{CH}_{2}\right)_{n} \mathrm{H}\right)$ with $\mathrm{HDO}$ gives $\mathrm{H}_{2}$ as main product (Supplementary Table 1, entries 5 and 8).

The reaction with $\left(\mathrm{HO}\left({ }^{13} \mathrm{CH}_{2}\right)_{n} \mathrm{H}\right)$ in $\mathrm{H}_{2} \mathrm{O}$, HDO or $\mathrm{D}_{2} \mathrm{O}$ resulted in the formation of ${ }^{13} \mathrm{CO}_{2}$ (Supplementary Table 1 , entries 10-12) besides the above mentioned H/D scrambling. The dehydrogenation of $\left(\mathrm{HO}\left(\mathrm{CH}_{2}\right)_{n} \mathrm{H}\right)$ in $\mathrm{H}_{2}^{18} \mathrm{O}$ (Supplementary Table 1, entry 6; Fig. 2) results in formation of $\mathrm{H}_{2}$, carbon dioxide $\mathrm{C}^{18} \mathrm{O}_{2}, \mathrm{C}\left({ }^{16} \mathrm{O}^{18} \mathrm{O}\right)$ and $\mathrm{C}^{16} \mathrm{O}_{2}$ proving the complete incorporation of one molecule of water into $\mathrm{FA}$ forming methanediol, including additional oxygen scrambeling giving all three ${ }^{16} \mathrm{O} /{ }^{18} \mathrm{O}$-labelled carbon dioxide species (Fig. 2). Moreover, the formation of ${ }^{18} \mathrm{O}_{2}$ (Fig. 2) indicates that water is oxidized at least partially in another reaction pathway probably involving ruthenium hydrides and hydroxo-bridged ruthenium dimers. Note, hydroxo-bridged dimers are readily formed in presence of the water ${ }^{37}$. Hence, this can be assigned as indirect water-splitting resulting in solely gaseous products. Furthermore, we would like to emphasize that water-splitting has not been observed in absence of a FA source.

In situ characterization by NMR. Analysis of the reaction mixture by one- and two-dimensional (2D) ${ }^{1} \mathrm{H}$ and ${ }^{13} \mathrm{C}$ NMR experiments provided evidence for the presence of a dinuclear ruthenium hydride $\left[(\mathrm{Ru}(\mathrm{p} \text {-cymene }))_{2} \mu-\mathrm{H}\left(\mu-\mathrm{HCO}_{2}\right) \mu-\mathrm{Cl}\right]^{+} \mathbf{3}$
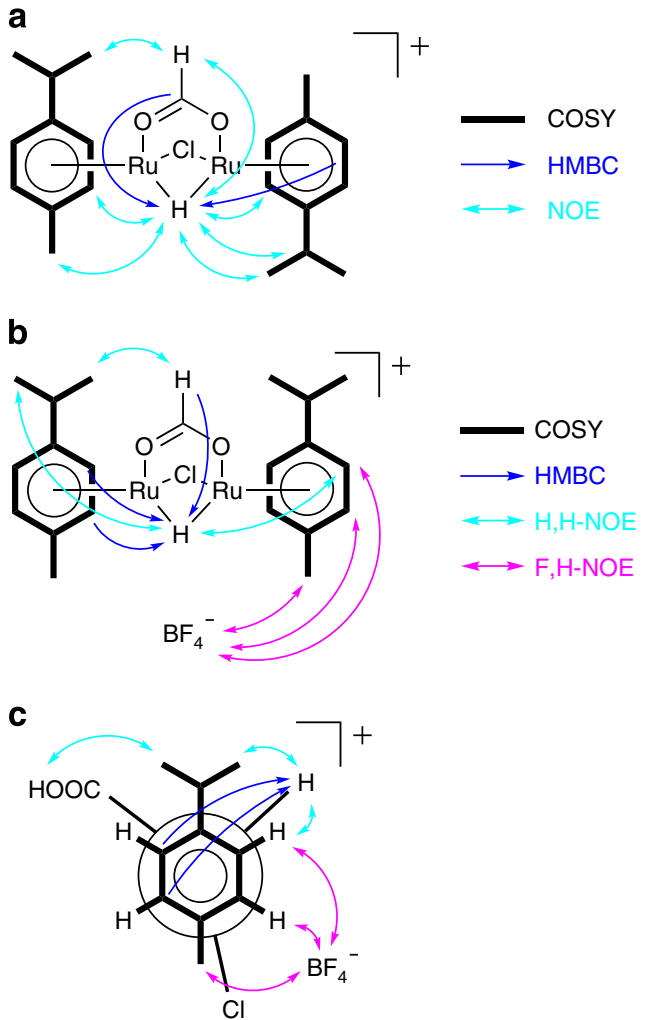

Figure 3 | Visualization of NMR results. Depiction of the correlated spectroscopy (COSY), nuclear overhauser effect (NOE) contacts and $\mathrm{H}, \mathrm{C}$ long range correlations in (a) $\left[(\mathrm{Ru}(\mathrm{p} \text {-cymene }))_{2} \mu-\mathrm{H}\left(\mathrm{HCO}_{2}\right) \mu-\mathrm{Cl}\right]+\mathrm{Cl}^{-}$ $\mathbf{3}$ (in water) (b) for $\mathbf{3}-\mathbf{B F}_{\mathbf{4}}$ (in $\mathrm{CD}_{2} \mathrm{Cl}_{2}$; front view) and (c) for $\mathbf{3}-\mathbf{B F}_{\mathbf{4}}$ (in $\mathrm{CD}_{2} \mathrm{Cl}_{2}$; side view)

(Fig. 3). Coupling patterns observed for the p-cymene ligand indicate asymmetric $\mathrm{Ru}$ centers, and integration of the ${ }^{1} \mathrm{H}$ NMR signals allows to conclude that the catalyst is a dinuclear monohydrido complex. Chemical shifts of the ligand system are in good agreement with the ones observed for similar, carboxylate complexes $^{39}$. There is only one type of arene ligand present, which shows clearly a H,C long range correlation to the bridging hydride signal at -7.08 . Another long range connectivity is observed between the bridging formate unit and the hydride. In addition, through-space couplings were detected by way of $2 \mathrm{D}$ $\mathrm{H}, \mathrm{H}$ nuclear overhauser effect spectroscopy experiments: cross peaks revealed interactions between p-cymene ligand and hydride, as well as proximity between p-cymene and formiate (Supplementary Figs 6-24; Supplementary Table 2). Besides the compound described above, other $\mathrm{Ru}$ complexes were also visible in the ${ }^{1} \mathrm{H}$ NMR spectrum: besides traces of $\left[(\mathrm{Ru}(\mathrm{p} \text {-cymene }))_{2}(\mu\right.$ $\left.\mathrm{Cl})_{2} \mathrm{Cl}_{2}\right] \mathbf{1}$ and its hydrolysis products, for example, $[(\mathrm{Ru}(\mathrm{p}-$ cymene $\left.))_{2}(\mu-\mathrm{OH})_{3}\right]^{+} 2$, at least one other Ru(p-cymene) complex could be identified. These three additional species are in chemical exchange, as evidenced by $\mathrm{H}, \mathrm{H}$ EXchange SpectroscopY experiments, most likely exchange between chlorido and hydroxo ligands (vide infra) ${ }^{37,40}$. In contrast to the previously reported acetato complexes ${ }^{39}$, the solute dynamic formiato complex 3 with $\mathrm{Cl}^{-}$as counter ion is only stable in solution in presence of methanediol or formic acid in water, thus isolation of $\mathbf{3}$ as chloride salt was not possible (Supplementary Figs 6 and 7), but we achieved the isolation as $\mathbf{B F}_{4}$-salt $\mathbf{3}-\mathbf{B F}_{\mathbf{4}}$ (vide infra).

In situ characterization by ESI-MS. Further analysis of aliquots of the liquid phase of $\left(\mathrm{HO}\left(\mathrm{CH}_{2}\right)_{n} \mathrm{H}\right)$ in $\mathrm{H}_{2} \mathrm{O}$ by means of ESI-MS 
showed that several ruthenium species are present, taking into account the isotope pattern of ruthenium (Supplementary Table 1; Supplementary Figs 25 and 26). Only one of them incorporates a formiate-bridging ligand and it can be assigned to $\left.[(\mathrm{Ru} \text { (p-cymene }))_{2} \mu-\mathrm{H}\left(\mu-\mathrm{HCO}_{2}\right) \mu-\mathrm{Cl}\right]^{+} \mathbf{3}$ (vide supra) and its isotopologues 4-8 (Supplementary Table 1). A previous report about formic acid dehydrogenation assigned the cation as $\left[(\mathrm{Ru}(\mathrm{p} \text {-cymene }))_{2} \mathrm{H}\left(\mu-\mathrm{HCO}_{2}\right) \mu-\mathrm{Cl}\right]^{+}$by means of ESI-MS experiments $^{8}$. The other species are formed when $[\mathrm{Ru}(\mathrm{p}$ cymene $\left.) \mathrm{Cl}_{2}\right]_{2} \mathbf{1}$ is dissolved in water under slightly acidic conditions; for example, $\left[(\mathrm{Ru}(\mathrm{p} \text {-cymene }))_{2}(\mu-\mathrm{OH})_{3}\right]^{+} 2$ (vide supra; for more examples see Supplementary Figs 25 and 26) ${ }^{37,40}$. In the present case, we can distinguish between ruthenium dimers bridged by combinations of formiato, hydrido, chlorido or hydroxo ligands (Supplementary Figs 25 and 26). Among them, the dimeric formiate- and hydride-bridged ruthenium complex 3 can be taken into account to play a role in the methanediol dehydrogenation owing to reported activity of ruthenium dinuclear complexes in formic acid dehydrogenation ${ }^{8,38}$. The analysis of aliquots of the liquid phase of the above discussed labelling experiments allows the assignment of complexes that reacted with methanediol. The formiato-bridged ruthenium dimer shows isotope shifts when labelled with ${ }^{2} \mathrm{H},{ }^{13} \mathrm{C}$ and ${ }^{18} \mathrm{O}$ (Fig. 4). The latter experiment proves again that water participates in the process also as a source of hydrogen via the methanediol formation and dehydrogenation. The labelled

a

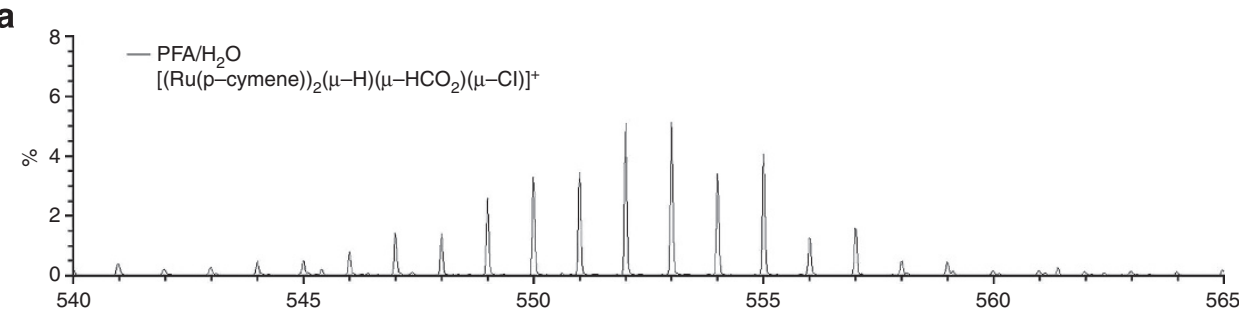

b

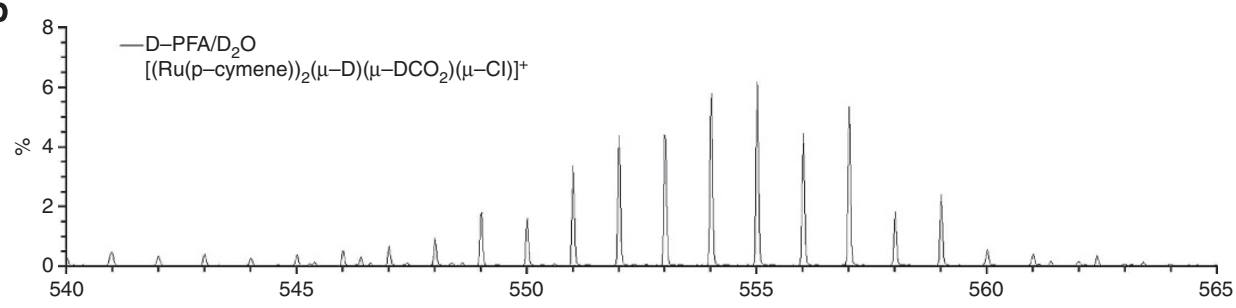

c

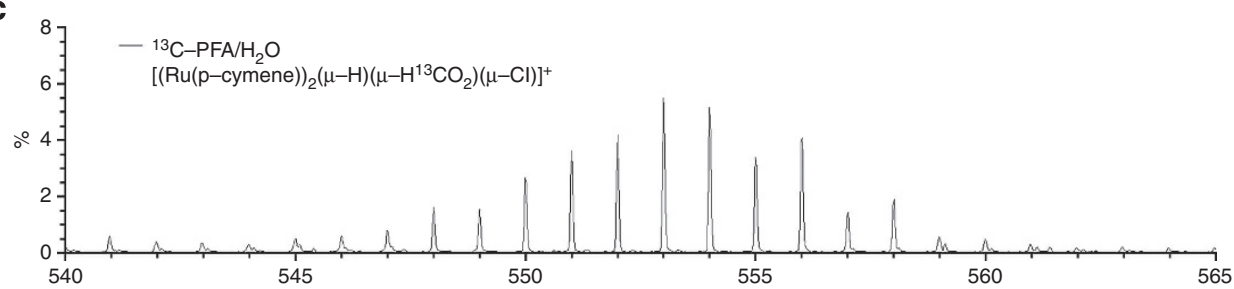

d

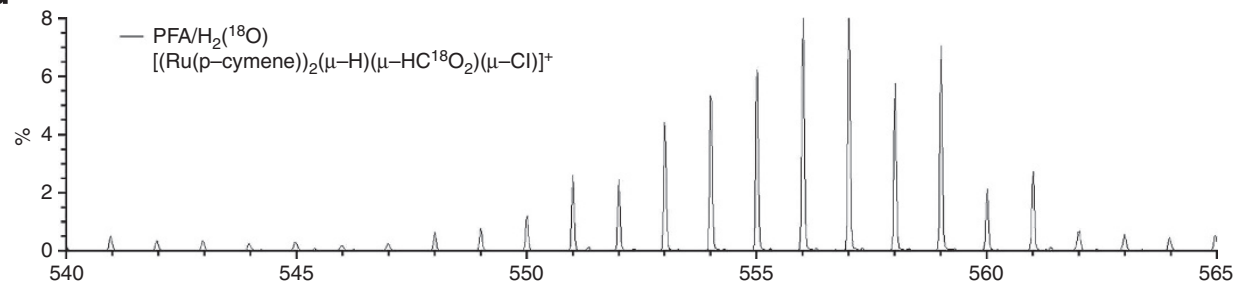

e

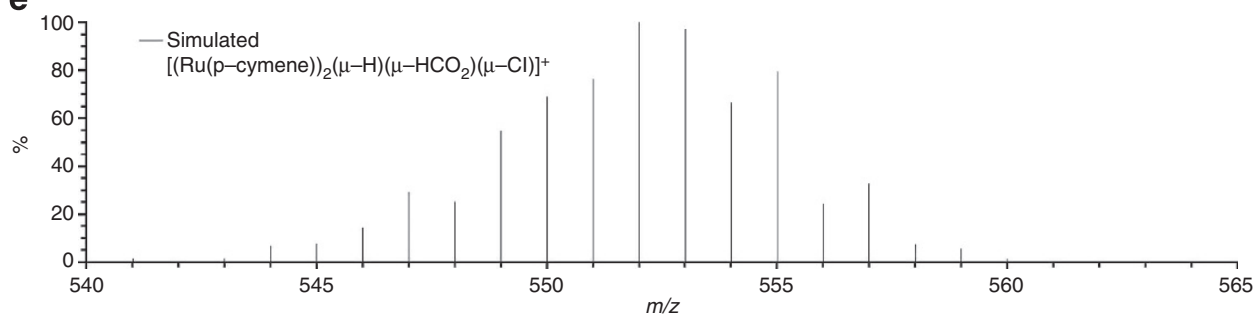

Figure 4 | ESI-MS spectrograms of the cations. (a) $\left[\left(\mathrm{Ru}(\mathrm{p} \text {-cymene) })_{2} \mu-\mathrm{H}\left(\mathrm{HCO}_{2}\right) \mu\right.\right.$-Cl] ${ }^{+} \mathbf{3}$ (pFA in $\mathrm{H}_{2} \mathrm{O}, \mathrm{M}=553$; Supplementary Table 1, entry 3), (b) $\left[\left(\mathrm{Ru}(\mathrm{p} \text {-cymene) })_{2} \mu\right.\right.$-D $\left(\mathrm{DCO}_{2}\right) \mu$-Cl] 4 (D-pFA in $\mathrm{D}_{2} \mathrm{O}, \mathrm{M}=555$; Supplementary Table 1, entry 7$),(\mathbf{c})\left[(\mathrm{Ru}(\mathrm{p}-\mathrm{cymene}))_{2} \mu-\mathrm{H}\left(\mathrm{H}^{13} \mathrm{CO}{ }_{2}\right) \mu-\mathrm{Cl}\right]^{+} \mathbf{7}\left({ }^{13} \mathrm{C}-\mathrm{pFA}\right.$ in $\mathrm{H}_{2} \mathrm{O}, \mathrm{M}=554$; Supplementary Table 1, entry 10), (d) $\left[(\mathrm{Ru}(\mathrm{p} \text {-cymene }))_{2} \mu-\mathrm{H}\left(\mathrm{HC}^{18} \mathrm{O}_{2}\right) \mu\right.$-Cl] ${ }^{+} \mathbf{6}\left(\mathrm{pFA}\right.$ in $\mathrm{H}_{2}^{18} \mathrm{O}, \mathrm{M}=557$; Supplementary Table 1, entry 6) derived from the pFA and water dehydrogenation and (e) simulated MS spectrogram. 
complexes clearly show the characteristic isotope shifts and stay in agreement with simulated spectrograms (Fig. 4). Note, no anionic complexes were detected in the ESI $(-)-\mathrm{MS}$ mode.

Catalyst performance and isolation. Regarding the catalytic activity, we have strong evidence that complex $\mathbf{3}$ is an active species as indicated by NMR analysis and isotope-labelling experiments. Moreover, we found that metal nanoparticles are unlikely to be active for this reaction under these conditions, as control experiments with nanoparticles and supported metal catalysts showed no activity. Taking into account the identified dinuclear ruthenium species $\left[(\mathrm{Ru}(\mathrm{p} \text {-cymene }))_{2} \mu-\mathrm{H}\left(\mu-\mathrm{HCO}_{2}\right) \mu-\mathrm{Cl}\right]^{+} 3$ by NMR, ESI-MS and the gaseous composition by MS gas analysis, we envision that the catalytic process for methanediol dehydrogenation is similar to the reported formic acid dehydrogenation by dinuclear ruthenium complexes ${ }^{38}$. Regarding the optimization of the catalytic performance of the simultaneous FA dehydrogenation and water-splitting via methanediol, we considered the application of a $\mathrm{pH}$ buffer $\left(\mathrm{K}_{3} \mathrm{PO}_{4}\right)$, varied the catalyst loadings (Supplementary Fig. 2), FA concentration and temperature. Practical catalyst precursor loadings can be as low as $0.1 \mathrm{~mol} \%$ with the best performance at $95^{\circ} \mathrm{C}(368 \mathrm{~K})$. The application of a $\mathrm{pH}$ buffer seems to be beneficial, as we found that in absence of a $\mathrm{pH}$ buffer the solution becomes strongly acidic and with the increasing acidity the reaction rate drops. However, the conversions are stable between $\mathrm{pH} 2.4$ (75\%) and $\mathrm{pH} 9$ (73\%) with a maximum at $\mathrm{pH} 5.5(85 \%)$ and dropped to $53 \%$ at $\mathrm{pH} 1.4$. Therefore, a pH buffer is beneficial but not crucial, and makes the catalytic system applicable for a wide $\mathrm{pH}$ range of aqueous systems containing FA. Moreover, under basic conditions the gas flow becomes very intensive in the initial reaction period, therefore lower catalyst loadings $(<0.14 \mathrm{~mol} \%)$ can be used, respectively large FA loadings in diluted solution are more feasible for a controlled low flow of hydrogen.

Good performance for recycling experiments and long-term stability could be achieved with both aqueous FA or pFA in water as a hydrogen source. It was possible to obtain a continuous hydrogen production by simply recharging the aqueous phase with pFA (three times). Also, with large substrate loadings of aqueous FA, we obtained a stable gas flow over 2 days even at $65^{\circ} \mathrm{C}$. Since simultaneously water is consumed for the generation of the methanediol, after prolonged time water as fuel must be added as well.

For proving the role of complex 3 in the FA-assisted watersplitting, we succeeded to isolate the complex from the ongoing catalytic process as its $\mathrm{BF}_{4}$-salt $\left(\mathbf{3}-\mathbf{B F}_{\mathbf{4}}\right)$. Also we synthesized complex $\mathbf{3}-\mathbf{B F}_{\mathbf{4}}$ by treatment of complex $\mathbf{1}$ with formic acid. The NMR (Supplementary Figs 14-24; Supplementary Table 3) and ESI-MS data of the cationic complexes $\mathbf{3}$ and $\mathbf{3}-\mathbf{B F}_{\mathbf{4}}$ are in full agreement with each other. With the independently synthesized compound, which yielded NMR spectra (Supplementary Figs 14-24) that are in complete accordance with the ones obtained from the isolated complex, further characterization was obtained by diffusion and nuclear overhauser effect (NOE) NMR experiments (Supplementary Figs 14-24). Thus, for the $\mathbf{3}-\mathbf{B F}_{\mathbf{4}}$ complex, ion pairing and a site-specific coordination of the counter ion could be detected (for details see SI and Supplementary Figs 14-24). Consequently, we used the synthesized complex $\mathbf{3}-\mathbf{B F}_{\mathbf{4}}$ for the FA-assisted water-splitting and it revealed also high activity similar to the in situ system with complex $\mathbf{1 .}$

\section{Discussion}

The pure gaseous stream solely containing hydrogen and carbon dioxide resulting from the catalytic conversion of aqueous FA and pFA, respectively, methanediol, makes this proof of concept interesting for all types of hydrogen fuel cells using water and a liquid organic hydrogen carrier. In particular, the tuneable flow rate and easily separable gas mixture allows the application in engines, overcoming technical difficulties with pressure cylinders. The application of such air-stable catalysts may overcome drawbacks related to inert gas techniques. FA and pFA are prepared industrially by silver or metal oxide-catalysed dehydrogenation of methanol (Formox process). Methanol itself is accessible from carbon monoxide, from renewable sources ${ }^{41}$, or via carbon dioxide hydrogenation ${ }^{19}$. Therefore, an envisioned $\mathrm{CO}_{2}$ neutral approach would be to complete the circuit of our presented system by including the extruded $\mathrm{CO}_{2}$ through hydrogenation into methanol (ref. 19), which can be subsequently oxidized to FA or pFA via the Formox process, note that partial reduction of $\mathrm{CO}_{2}$ to $\mathrm{FA}$ is an unresolved issue (Fig. 5).

For mobile $\mathrm{H}_{2}$-fuelled devices, the $\mathrm{CO}_{2}$ capturing and the regeneration of the FA from $\mathrm{CO}_{2}$ might be decoupled from the fuel cell system. $\mathrm{CO}_{2}$ capturing and its hydrogenation is more suitable to be performed at industrial plants using $\mathrm{CO}_{2}$-containing exhaust gas streams rather than an on-board regeneration of the spent fuel. However, there are still some obstacles for future research regarding the straight forward conversion of carbon dioxide into FA, as until now FA is only accessible from methanol oxidation in a practical way. The homogeneous-catalysed dehydrogenation of aqueous FA and pFA solutions in our present work show a robust and air-stable method for hydrogen production at low temperature, mild conditions and tuneable rates. Previous limitations of homogeneous systems using formic acid or methanol as a hydrogen storage material, such as low weight efficiency (formic acid), application of air-sensitive catalysts (methanol) or gaseous side-products (CO) have been avoided. However, this approach is still limited to pFA or technical grade aqueous FA (37 wt\%) giving a $\mathrm{H}_{2}$ weight efficiency of about $5 \mathrm{wt} \%$, although methanediol has a hydrogen content of $8.4 \mathrm{wt} \%$. For this reason future studies will include the optimization to push the weight efficiency of this approach to its limit above $8 \mathrm{wt} \%$ to make it more attractive for potential application. Although the catalyst is active in basic and acidic solution, the $\mathrm{pH}$ value has to be taken into account for best catalytic activity, and this must be considered for tailoring the performance of future catalysts and overcome limitations in application. Furthermore, this approach might be suitable for simultaneous hydrogen production and decontamination of industrial wastewater with FA impurities-a waste-to-value approach. The latter aspect could be of interest as FA

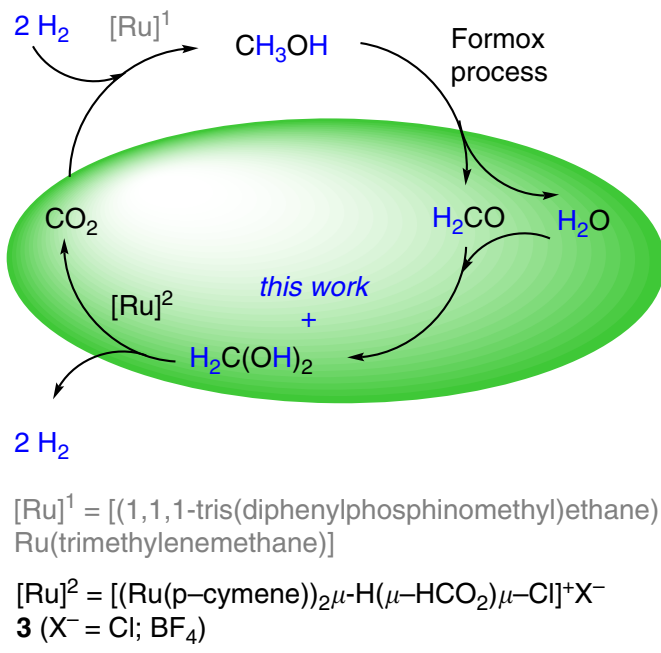

Figure 5 | Hydrogen storage cycle. A full cycle for a $\mathrm{CO}_{2}$-based hydrogen storage system including catalysts $\mathbf{3}$ or $\mathbf{3}-\mathbf{B F}_{\mathbf{4}}$ 
contamination of wastewater remains a worldwide problem to be solved, since it might be a step forward to overcome these obstacles.

\section{Methods}

General considerations. pFA was purchased from Alfa Aesar. pFA- $\mathrm{D}_{2}$, hydrogenoxide- ${ }^{18} \mathrm{O}, \mathrm{D}_{2}$-FA solution $\left(20 \mathrm{wt} \% \mathrm{FA}\right.$ in $\left.\mathrm{D}_{2} \mathrm{O}\right)$, non-deuterated $\mathrm{FA}$ (37 wt\% FA in $\mathrm{H}_{2} \mathrm{O}$ ) and $\left[\mathrm{RuCl}_{2}(p \text {-cymene })\right]_{2}$ were purchased from Sigma Aldrich. pFA $-{ }^{13} \mathrm{C}$ was purchased from Cambridge Isotope Laboratories. All chemicals were used without further purification. If not mentioned separately, deionized water was used for all experiments. The catalytic reactions, catalyst isolation and catalyst syntheses were usually performed at least three times.

All dehydrogenation reactions were carried out without precautions against moisture or oxygen unless otherwise stated. All dehydrogenation data were corrected by experimental data of empty glass reactors at the set temperature to compensate for thermal expansion. The amount of released gas was determined with a mass flow meter of the manufacturer MKS connected via an analogue connection to a desktop computer. MS investigations (gas composition) in the gas phase were conducted with a HPR-20 gas analysis system by Hiden Analytical and were directly connected to the catalysis setup (Supplementary Fig. 28). The HPR-20 QIC (Hiden Analytical) has a MS detection limit $<0.09$ p.p.m. as xenon in air is detectable. Note the MS has sensitivity down to partial pressures of $10^{-10}$ torr (note: spectrometer-specific unit is torr not $\mathrm{MPa}$ ). The data were recorded with the software RealView 3.0 by ABACOM. Data processing was conducted with QtiPlot0.9.9 (Ion Vasilief).

Characterization and physical measurements. ${ }^{1} \mathrm{H},{ }^{2} \mathrm{H}$ and ${ }^{13} \mathrm{C}$ NMR spectra were recorded on Bruker Avance $400 \mathrm{MHz}$, Bruker Avance $300 \mathrm{MHz}$, Bruker Avance III $500 \mathrm{MHz}$ or Bruker Avance II ${ }^{+} 600 \mathrm{MHz}$ spectrometers. ${ }^{1} \mathrm{H},{ }^{19} \mathrm{~F}$, ${ }^{11} \mathrm{~B}$ and ${ }^{13} \mathrm{C}$ NMR chemical shifts are reported in p.p.m. NMR data are presented as follows: chemical shift, multiplicity ( $\mathrm{s}$, singlet; $\mathrm{d}$, doublet; $\mathrm{t}$, triplet; $\mathrm{q}$, quadruplet; $\mathrm{m}$, multiplet and/or multiple resonances), coupling constants are given in Hertz $(\mathrm{Hz})$, relative signal intensities $\left({ }^{1} \mathrm{H}\right)$ were obtained by integration. All NMR signals were assigned on the basis of ${ }^{1} \mathrm{H}$ and ${ }^{13} \mathrm{C}\left({ }^{1} \mathrm{H}\right)$, gradient-edited $\mathrm{H}-\mathrm{H}$ correlated spectroscopy, $\mathrm{H}-\mathrm{H}$ nuclear overhauser effect spectroscopy, $\mathrm{H}-\mathrm{C}$ heteronuclear multiple-quantum correlation and $\mathrm{H}-\mathrm{C}$ heteronuclear multiple bond correlation experiments. Water and FA signals were suppressed by standard solvent suppression sequences. Spectra were recorded at $298 \mathrm{~K}$ if not otherwise indicated. NMR samples of complex 3 were prepared by dissolving $20 \mathrm{mg}(0.03 \mathrm{mmol})$ of $\left[\mathrm{RuCl}_{2} \text { (p-cymene) }\right]_{2}$ and $7-8 \mathrm{mg}$ pFA with $675 \mu \mathrm{H}_{2} \mathrm{O}$ or $\mathrm{D}_{2} \mathrm{O}$ in a gas chromatography vial equipped with a magnetic stirring bar. After addition of $1 \mu \mathrm{l}$ of $1 \mathrm{M}$ aqueous $\mathrm{H}_{2} \mathrm{SO}_{4}$ solution, the sample was stirred at $95^{\circ} \mathrm{C}(368 \mathrm{~K})$ for $35 \mathrm{~min}$. The mixture was cooled to room temperature and transferred to a 5-mm NMR tube. In case of $\mathrm{H}_{2} \mathrm{O}$ solutions, an insert containing $100 \mu \mathrm{l}$ of $\mathrm{D}_{2} \mathrm{O}$ was introduced to lock the sample for NMR measurements. The 2D H-F HOESY experiments were performed with the isolated/synthesized complex $\mathbf{3}-\mathbf{B F}_{4}$ analysed in $\mathrm{CD}_{2} \mathrm{Cl}_{2}$. HOESY experiments were acquired using a gradient-selected version ${ }^{42}$. Semiquantitative spectra were acquired using a 3.5-s relaxation delay and 700-ms mixing time. For the determination of self-diffusion coefficients, ${ }^{1} \mathrm{H}$ - and ${ }^{19} \mathrm{~F}$-PGSE NMR experiments were carried out for $3-\mathbf{B F}_{4}$ in $\mathrm{CD}_{2} \mathrm{Cl}_{2}$ at $298 \mathrm{~K}$ for cation $\left({ }^{1} \mathrm{H}\right)$ and anion $\left({ }^{19} \mathrm{~F}\right)$. Measurements were performed by using a stimulated echo pulse sequence with LED implemented ${ }^{43}$ on a Bruker Avance $400 \mathrm{MHz}$ spectrometer equipped with a GAB gradient amplifier and a triple resonance broad band inversed (TBI) probe with a Z-gradient coil. The diffusion coefficients for complex 3- $\mathrm{BF}_{4}$ (cation $D=4.1^{*} 10^{-9} \mathrm{~m}^{2} \mathrm{~s}^{-1}$ and anion $D=4.8^{*} 10^{-9} \mathrm{~m}^{2} \mathrm{~s}^{-1}$ ) indicate together with strong NOE contacts observable from H,F HOESY spectra the presence of ion pairing.

A small portion of the NMR solution was also used for ESI-MS experiments (vide infra): for this purpose, the sample was further diluted to a concentration of $1 \mathrm{mg} \mathrm{ml}^{-1}$. From this stock solution one drop was diluted in $1.5 \mathrm{ml} \mathrm{H}_{2} \mathrm{O}$ or $\mathrm{D}_{2} \mathrm{O}$; the sample with $\mathrm{H}_{2}{ }^{18} \mathrm{O}$ was diluted with acetonitrile to avoid oxygen scrambeling with $\mathrm{H}_{2} \mathrm{O}$. ESI-MS investigations were performed on a LTQ XL Thermo Scientific.

Dehydrogenation of neat aqueous FA solutions. Exemplary experiment: $12.9 \mu \mathrm{mol}(0.1 \mathrm{~mol} \%)\left[\mathrm{RuCl}_{2}(p \text {-cymene })\right]_{2} \mathbf{1}$ were added to $13.55 \mathrm{mmol}$ of an aqueous FA solution (37 wt\% FA) into a small round-bottomed flask, the flask was connected to the measuring setup. The reaction mixture was heated to $95^{\circ} \mathrm{C}$ $(368 \mathrm{~K})$ yielding $300 \mathrm{ml}$ gas $\left(\mathrm{H}_{2} / \mathrm{CO}_{2}\right)$ in $200 \mathrm{~min}$ for complex $\mathbf{1}$. The same protocol has been used applying $\left[(\mathrm{Ru}(\mathrm{p}-\mathrm{cymene}))_{2} \mu-\mathrm{H}\left(\mu-\mathrm{HCO}_{2}\right) \mu-\mathrm{Cl}\right]^{+} \mathrm{BF}_{4}^{-} \mathbf{3}-\mathrm{BF}_{4}$ as a catalyst yielding $340 \mathrm{ml}$ gas (with a $\mathrm{K}_{3} \mathrm{PO}_{4} \mathrm{pH}$ buffer) and $180 \mathrm{ml}$ after $200 \mathrm{~min}$ under base-free conditions.

Dehydrogenation of aqueous FA solutions. Exemplary experiment: $18.1 \mu \mathrm{mol}$ $(0.14 \mathrm{~mol} \%)\left[\mathrm{RuCl}_{2}(p \text {-cymene })\right]_{2}$ were added with $1.9 \mathrm{ml}$ water and $13.55 \mathrm{mmol}$ of an aqueous FA solution ( $37 \mathrm{wt} \% \mathrm{FA}$ ) into a small round-bottomed flask. After $0.21 \mathrm{mmol}(44.6 \mathrm{mg}) \mathrm{K}_{3} \mathrm{PO}_{4}$ were added to the content, the flask was connected to the measuring setup. The reaction mixture was heated to $95^{\circ} \mathrm{C}(368 \mathrm{~K}$ ) giving $25 \%$ conversion $(\mathrm{TON}=188)$ already after $67 \mathrm{~min}$.
Dehydrogenation of pFA in water (example). Exemplary experiment: $0.13 \mathrm{mmol}$ $\left[\operatorname{RuCl}_{2}(p \text {-cymene })\right]_{2}$ were added with $2.7 \mathrm{ml}$ water and $1.0 \mathrm{mmol} \mathrm{pFA}$ into a smal round-bottomed flask. After $5.2 \mu \mathrm{mol}(5.2 \mu \mathrm{l})$ of $1 \mathrm{M} \mathrm{H}_{2} \mathrm{SO}_{4}$ (aqueous) were added to the content, the flask was connected to the measuring setup. The reaction mixture was heated to $95^{\circ} \mathrm{C}(368 \mathrm{~K})$ for 74 min giving $75 \%$ conversion.

Isolation of complex $\mathbf{3}-\mathbf{B F}_{\mathbf{4}} \cdot\left[\mathrm{RuCl}_{2}(p-\text { cymene })\right]_{2} \mathbf{1}(0.13 \mathrm{mmol}(80 \mathrm{mg}))$ and $1 \mathrm{mmol}(30.0 \mathrm{mg}) \mathrm{pFA}$ were suspended in $2.5 \mathrm{ml}$ water. The mixture was heated to $95^{\circ} \mathrm{C}(368 \mathrm{~K})$ and stirred for $45 \mathrm{~min}$. The solution was cooled down to room temperature and filtered. $\mathrm{NaBF}_{4}(0.13 \mathrm{mmol}(14.3 \mathrm{mg}))$ were added to the filtrate and stirred for $2 \mathrm{~min}$. The precipitate was filtered off, washed two times with $0.5 \mathrm{ml}$ water and dried under reduced pressure, the solid material was analysed by NMR staying in full agreement with the data obtained for the cation of complex $\mathbf{3}$. Melting point: $164-166^{\circ} \mathrm{C}(437-439 \mathrm{~K})$ (decomposition); ${ }^{1} \mathrm{H} \mathrm{NMR}(300 \mathrm{MHz}$, $\left.\mathrm{CD}_{2} \mathrm{Cl}_{2}\right): \delta 6.83(\mathrm{~d}, J=0.8 \mathrm{~Hz}, 1 \mathrm{H}), 6.51(\mathrm{~d}, J=5.9 \mathrm{~Hz}, 1 \mathrm{H}), 6.17(\mathrm{~d}, J=6.1 \mathrm{~Hz}$, $1 \mathrm{H}), 5.79(\mathrm{~d}, J=6.0 \mathrm{~Hz}, 1 \mathrm{H}), 5.44(\mathrm{~d}, J=5.9 \mathrm{~Hz}, 1 \mathrm{H}), 2.70$ (hept, $J=6.9 \mathrm{~Hz}, 1 \mathrm{H})$ $2.12(\mathrm{~s}, 3 \mathrm{H}), 1.31(\mathrm{~d}, J=6.9 \mathrm{~Hz}, 3 \mathrm{H}), 1.30(\mathrm{~d}, 6.9 \mathrm{~Hz}, 3 \mathrm{H}),-7.26(\mathrm{~s}, 1 \mathrm{H}) ;{ }^{13} \mathrm{C}$ NMR ( $75 \mathrm{MHz}, \mathrm{CD}_{2} \mathrm{Cl}_{2}$ ): $\delta 174.9,104.6,97.8,86.2,84.3,80.9,78.8,31.6,22.7,21.8,19.2$; ${ }^{19} \mathrm{~F}$ NMR $\left(282 \mathrm{MHz}, \mathrm{CD}_{2} \mathrm{Cl}_{2}\right): \delta-152.0(\mathrm{q}, J=1.1 \mathrm{~Hz}) ;{ }^{11} \mathrm{~B}$ NMR $(282 \mathrm{MHz}$, $\left.\mathrm{CD}_{2} \mathrm{Cl}_{2}\right): \delta-0.9$ (quin, $J=1.1 \mathrm{~Hz}$ ); $\mathrm{HRMS}(m / z)$ : $[\mathrm{M}]^{+}$calcd. for $\mathrm{C}_{21} \mathrm{ClH}_{30} \mathrm{O}_{2} \mathrm{Ru}_{2}$, 553.0016; found, 553.0018 (see Supplementary Fig. 27).

Synthesis of complex 3-BF4 using formic acid. A round-bottom flask was charged with $0.65 \mathrm{mmol}(400 \mathrm{mg})\left[\mathrm{RuCl}_{2}(p \text {-cymene) }]_{2} \mathbf{1}\right.$ and $20 \mathrm{ml}$ water. Formic acid $(1.5 \mathrm{mmol}(57 \mu \mathrm{l}))$ was added and the mixture was heated to $95^{\circ} \mathrm{C}(368 \mathrm{~K})$ for $15 \mathrm{~min}$. The solution was quickly cooled down to room temperature and $0.65 \mathrm{mmol}$ $(71.4 \mathrm{mg}) \mathrm{NaBF}_{4}$ was added. The precipitate was filtered off, washed two times with $1.5 \mathrm{ml}$ water and dried in vacuo yielding $180 \mathrm{mg}(0.28 \mathrm{mmol}) 3-\mathbf{B F}_{4}$ ( $\mu$-chloro, - $\mu$-formiato, $\mu$-hydrido( $p$-cymene)ruthenium(II) dimer tetrafluoroborate salt) as orange-red powder, the solid material was analysed by NMR and ESI-MS staying in full agreement with the data obtained for the complex $\mathbf{3}-\mathbf{B F}_{4}$ as isolated using the procedure for isolation of complex $\mathbf{3}-\mathbf{B F}_{4}$

\section{References}

1. Steele, B. C. H. \& Heinzel, A. Materials for fuel-cell technologies. Nature 414, 345-352 (2001).

2. Prechtl, M. H. G. \& Sahler, S. Hydrogen storage using ionic liquid media. Curr. Org. Chem. 17, 220-228 (2013).

3. Sahler, S. \& Prechtl, M. H. G. Advancement in molecular hydrogen storage systems. Chemcatchem 3, 1257-1259 (2011).

4. Schlapbach, L. \& Zuttel, A. Hydrogen-storage materials for mobile applications. Nature 414, 353-358 (2001).

5. Schuth, F., Bogdanovic, B. \& Felderhoff, M. Light metal hydrides and complex hydrides for hydrogen storage. Chem. Commun. 20, 2249-2258 (2004).

6. Filinchuk, Y., Chernyshov, D., Nevidomskyy, A. \& Dmitriev, V. High-pressure polymorphism as a step towards destabilization of LiBH4. Angew. Chem. Int. Ed. 47, 529-532 (2008)

7. Sahler, S., Konnerth, H., Knoblauch, N. \& Prechtl, M. H. G. Hydrogen storage in amine boranes: Ionic liquid supported thermal dehydrogenation of ethylene diamine bisborane. Int. J. Hydrogen Energ. 38, 3283-3290 (2013).

8. Scholten, J. D., Prechtl, M. H. G. \& Dupont, J. Decomposition of formic acid catalyzed by a phosphine-free ruthenium complex in a task-specific ionic liquid. Chemcatchem 2, 1265-1270 (2010).

9. Moret, S., Dyson, P. J. \& Laurenczy, G. Direct, in situ determination of $\mathrm{pH}$ and solute concentrations in formic acid dehydrogenation and $\mathrm{CO}_{2}$ hydrogenation in pressurised aqueous solutions using H-1 and C-13 NMR spectroscopy. Dalton Trans. 42, 4353-4356 (2013).

10. Boddien, A. et al. Towards the development of a hydrogen battery. Energ. Environ. Sci. 5, 8907-8911 (2012).

11. Grasemann, M. \& Laurenczy, G. Formic acid as a hydrogen source-recent developments and future trends. Energ. Environ. Sci. 5, 8171-8181 (2012).

12. Boddien, A. et al. Efficient dehydrogenation of formic acid using an iron catalyst. Science 333, 1733-1736 (2011)

13. Papp, G., Csorba, J., Laurenczy, G. \& Joo, F. A charge/discharge device for chemical hydrogen storage and generation. Angew. Chem. Int. Ed. 50, 10433-10435 (2011).

14. Federsel, C. et al. A well-defined iron catalyst for the reduction of bicarbonates and carbon dioxide to formates, alkyl formates, and formamides. Angew. Chem. Int. Ed. 49, 9777-9780 (2010).

15. Fellay, C., Dyson, P. J. \& Laurenczy, G. A viable hydrogen-storage system based on selective formic acid decomposition with a ruthenium catalyst. Angew. Chem. Int. Ed. Engl. 47, 3966-3968 (2008).

16. Loges, B., Boddien, A., Junge, H. \& Beller, M. Controlled generation of hydrogen from formic acid amine adducts at room temperature and application in $\mathrm{H}(2) / \mathrm{O}(2)$ fuel cells. Angew. Chem. Int. Ed. Engl. 47, 3962-3965 (2008).

17. Mars, P., Scholten, J. J. F. \& Zwietering, P. The catalytic decomposition of formic acid. Adv. Catal. 14, 35-113 (1963). 
18. Nielsen, M. et al. Low-temperature aqueous-phase methanol dehydrogenation to hydrogen and carbon dioxide. Nature 495, 85-89 (2013).

19. Wesselbaum, S., vom Stein, T., Klankermayer, J. \& Leitner, W Hydrogenation of carbon dioxide to methanol by using a homogeneous ruthenium-phosphine catalyst. Angew. Chem. Int. Ed. 51, 7499-7502 (2012).

20. Meaburn, G. M., Mellows, F. W. \& Reiffste, A. Production of hydrogen in radiolysis of methanol vapour. Nature 204, 1301-1302 (1964).

21. Olah, G. A. Beyond oil and gas: the methanol economy. Angew. Chem. Int. Ed. 44, 2636-2639 (2005).

22. Schuth, F. Challenges in hydrogen storage. Eur. Phys. J. Special Topics 176, 155-166 (2009).

23. Eberle, U., Felderhoff, M. \& Schuth, F. Chemical and physical solutions for hydrogen storage. Angew. Chem. Int. Ed. Engl. 48, 6608-6630 (2009).

24. Kohl, S. W. et al. Consecutive thermal H-2 and light-induced O-2 evolution from water promoted by a metal complex. Science 324, 74-77 (2009).

25. Prechtl, M. H. G. et al. Direct coupling of alcohols to form esters and amides with evolution of H-2 using in situ formed ruthenium catalysts. Catal. Sci. Technol. 2, 2039-2042 (2012).

26. Prechtl, M. H. G., Heim, L. E. \& Schloerer, N. E. H2-Produktion-Verwendung von Formaldehyd, Paraformaldehyd, Wasser und Methandiol (Formaldehydhydrat) zur Wasserstoffproduktion (H2, HD, D2, T2) und Energiespeicherung. German patent 1020130113792 (2013).

27. Rameshan, C. et al. Hydrogen production by methanol steam reforming on copper boosted by zinc-assisted water activation. Angew. Chem. Int. Ed. Engl. 51, 3002-3006 (2012).

28. Kniep, B. L. et al. Rational design of nanostructured copper-zinc oxide catalysts for the steam reforming of methanol. Angew. Chem. Int. Ed. Engl. 43, 112-115 (2004).

29. Lin, Y. G. et al. Nanostructured zinc oxide nanorods with copper nanoparticles as a microreformation catalyst. Angew. Chem. Int. Ed. Engl. 48, 7586-7590 (2009).

30. Rameshan, C. et al. Subsurface-controlled CO2 selectivity of PdZn near-surface alloys in H-2 generation by methanol steam reforming. Angew. Chem. Int. Ed. Engl. 49, 3224-3227 (2010).

31. Behrens, M. \& Schlogl, R. How to prepare a good $\mathrm{Cu} / \mathrm{ZnO}$ catalyst or the role of solid state chemistry for the Synthesis of nanostructured catalysts. Z. Anorg. Allg. Chem. 639, 2683-2695 (2013).

32. Friedrich, M., Penner, S., Heggen, M. \& Armbruster, M. High CO2 selectivity in methanol steam reforming through $\mathrm{ZnPd} / \mathrm{ZnO}$ teamwork. Angew. Chem. Int. Ed. Engl. 52, 4389-4392 (2013).

33. Olah, G. A. The Role of catalysis in replacing oil by renewable methanol using carbon dioxide capture and recycling (CCR). Catal. Lett. 143, 983-987 (2013).

34. Bell, R. P. The Reversible Hydration of Carbonyl Compounds Vol. 4 Elsevier, 1966).

35. Anslyn, E. V. \& Dougherty, D. A. Modern physical organic chemistry 544 University Science Books, 2006)

36. Wakai, C., Yoshida, K., Tsujino, Y., Matubayasi, N. \& Nakahara, M. Effect of concentration, acid, temperature, and metal on competitive reaction pathways for decarbonylation and decarboxylation of formic acid in hot water. Chem. Lett. 33, 572-573 (2004).
37. Biro, L., Farkas, E. \& Buglyo, P. Hydrolytic behaviour and chloride ion binding capability of $[\mathrm{Ru}(\mathrm{eta}(6)-\mathrm{p}-\mathrm{cym})(\mathrm{H} 2 \mathrm{O})(3)](2+)$ : a solution equilibrium study. Dalton Trans. 41, 285-291 (2012).

38. Gao, Y., Kuncheria, J., Yap, G. P. A. \& Puddephatt, R. J. An efficient binuclear catalyst for decomposition of formic acid. Chem. Commun. 21, 2365-2366 (1998).

39. Bennett, M. A. \& Ennett, J. P. Synthesis and spectroscopic characterization of dinuclear mono(Mu-Hydrido) arene complexes of divalent ruthenium. Organometallics 3, 1365-1374 (1984).

40. Biro, L., Balogh, E. \& Buglyo, P. Interaction between [Ru(eta(6)-pcym $)(\mathrm{H} 2 \mathrm{O})(3)](2+)$ and DL-serine or DL-isoserine: the role of the side chain alcoholic $\mathrm{OH}$ group in metal ion binding. J. Organomet. Chem. 734, 61-68 (2013).

41. Cortright, R. D., Davda, R. R. \& Dumesic, J. A. Hydrogen from catalytic reforming of biomass-derived hydrocarbons in liquid water. Nature 418, 964-967 (2002).

42. Bauer, W. Pulsed field gradient 'inverse' HOESY applied to the isotope pairs H-1,P-31 and H-1,Li-7. Magn. Reson. Chem. 34, 532-537 (1996).

43. Wu, D. H., Chen, A. D. \& Johnson, C. S. An improved diffusion-ordered spectroscopy experiment incorporating bipolar-gradient pulses. J. Magn. Reson. Ser. A 115, 260-264 (1995).

\section{Acknowledgements}

This research was supported by the 'Ministerium für Innovation, Wissenschaft und Forschung NRW' (MIWF-NRW) under the Energy Research Programme for the Scientist Returnee Award 2009 (MaNCatal- $\left.\mathrm{H}_{2}\right)$ for M.H.G.P. and by the University of Cologne. For additional access to ESI-MS analysis, we like to thank C. Limberg (HU Berlin).

\section{Author contributions}

L.E.H. carried out catalytic and stoichiometric experiments, measured analytical data and performed NMR analysis. J.-H.C. performed NMR analysis. N.E.S. performed NMR analysis and wrote the manuscript. M.H.G.P. designed and directed the project and wrote the manuscript.

\section{Additional information}

Supplementary Information accompanies this paper at http://www.nature.com/ naturecommunications

Competing Financial Interests: A patent has been filed under 102013011379.2 at the German Patent Office DMPA.

Reprints and permission information is available online at http://npg.nature.com/ reprintsandpermissions/

How to cite this article: Heim, L.E. et al. Selective and mild hydrogen production using water and formaldehyde. Nat. Commun. 5:3621 doi: 10.1038/ncomms4621 (2014). 